\title{
EFEITO DE DIFERENTES PROCESSOS DE SOLDAGEM SOBRE A MICROESTRUTURA DO AÇO API X52*
}

\author{
Rômulo Mendes de Barros ${ }^{1}$ \\ Maurício dos Santos Vasconcellos ${ }^{2}$ \\ Monique Osório ${ }^{3}$ \\ Leonardo Bruno da Fonseca ${ }^{4}$ \\ Wilma CLemente de Lima Pinto ${ }^{5}$ \\ Ana Isabel de Carvalho Santana ${ }^{6}$
}

\section{Resumo}

Os aços API com classificação X52 são considerados aços alta resistência baixa liga (ARBL). Estes materiais possuem como principais características a elevada resistência mecânica, tenacidade e boa soldabilidade. Os aços API são muito utilizados para a produção de tubulações que realizam o transporte de água, petróleo, gás e derivados. A produção dos tubos envolve processos de soldagem, que podem provocar mudanças na microesturura do material. Dessa forma, pesquisas são realizadas com o objetivo de investigar a relação entre o processo de soldagem com a microestrutura e a resistência mecânica do material. Este trabalho tem como objetivo comparar dois processos de soldagem: GTAW (Gas Tungsten Arc Welding) e o SMAW (Shielded Metal Arc Welding), a fim de verificar a relação entre os diferentes processos e a microestrutura da junta soldada. Foram realizadas observações da macro e da micro estrutura. Verificou-se que a amostra soldada pelo processo GTAW apresentou uma microestutura com maior número de fases.

Palavras-chave: Aço API; Soldagem; Microestrutura.

\section{EFFECT OF DIFFERENTS WELDINGS PROCESS IN API X52 STEEL MICROSTRUCTURE}

\begin{abstract}
API steels classified as X52 are considered high strength low alloy steels (HSLA). These materials have as main characteristics the high mechanical resistance, toughness and good weldability. API steels are widely used API steels are widely used to transport water, oil, natural gas and derivatives. The production of the tubes involves welding processes, which can cause changes in the microstructure of the material. In this way, researches are carried out with the objective of investigating the relationship between the welding process, the microstructure and the mechanical strength of the material. This work aims to compare two welding processes: GTAW (Gas Tungsten Arc Welding) and SMAW (Shielded Metal Arc Welding), to verify the relationship between the different processes and the microstructure of the welded joint. Macro and micro structure observations were made. It was verified that the sample welded by the GTAW process has presented a microestuture with greater number of phases.
\end{abstract}

Keywords: Steel API; welding; microstructure.

1 (Aluno de iniciação), Laboratório de Eletroquímica e Microscopia de Materiais, CSPI, Fundação Centro Universitário Estadual da Zona Oeste - UEZO, Rio de Janeiro/RJ, Brasil.

2 (Aluno de iniciação), Laboratório de Eletroquímica e Microscopia de Materiais, CSPI, Fundação Centro Universitário Estadual da Zona Oeste - UEZO, Rio de Janeiro/RJ, Brasil.

3 Engenheiro Metalurgista, Mestre, Laboratório de Eletroquímica e Microscopia de Materiais, CSPI, Fundação Centro Universitário Estadual da Zona Oeste - UEZO, Rio de Janeiro/RJ, Brasil.

4 Física, Doutorado, professora, Centro Universitário de Volta Redonda - UNIFOA, Volta Redonda/RJ; Faculdade Senai Rio, Rio de Janeiro/RJ, Brasil.

5 Engenheira Química, Doutorado, professora Adjunto, Laboratório de Eletroquímica e Microscopia de Materiais, CSPI, Fundação Centro Universitário Estadual da Zona Oeste - UEZO, Rio de Janeiro/RJ, Brasil.

6 Química, Doutorado, professora Adjunto, Laboratório de Eletroquímica e Microscopia de Materiais, CSPI, Fundação Centro Universitário Estadual da Zona Oeste - UEZO, Rio de Janeiro/RJ, Brasil. 


\section{INTRODUÇÃO}

O aço pode ser considerado como uma das ligas metálicas mais amplamente utilizadas no meio industrial. Existem inúmeras classificações para os aços, essas classificações variam de acordo com a composição química, o processamento e as propriedades de cada liga. Uma das classificaçoes de aço que vêm sendo extensivamente utilizada na industria de petróleo e gás, offshore, e na industria de transporte em geral é a API (American Petroleum Institute). A norma API é responsável por especificar a fabricação de tubos (API 5L). Os aços API X52, são exemplos de materiais conhecidos como aços alta resistencia baixa liga ( $A B R L)$, e são um dos mais aplicados para a fabricação de tubos para transporte de água, óleo, gás etc. um dos mais utilizados pela indústria do petróleo para a passagem de óleo bruto e seus derivados [1 - 3].

Processos de soldagem são comumente aplicados aos aços API, tanto no processo de fabricação quanto no processo de montagem dos dutos. No entanto, como na maior parte das ligas metálicas, processos que envolvem transferência de calor, tais como os processos de soldagem podem provocar alterações na microestrutura do material, que acarretariam em diminuição das propriedades do material [3 - 5]. Devido a consideravel importancia industrial dos aços API, muitas pesquisas vêm sendo realizadas com o objetivo de investigar a relação entre processos soldagem com a microestrutura e as propriedades do material, tais como resistencia mecânica e susceptibilidade à corrosão.

Este trabalho tem como objetivo avaliar a relação entre dois diferentes processos de soldagem realizados sobre um aço API X52, e a microestrutura observada nas diferentes zonas (zona de fusão, zona termicamente afetada e metal de base) do material.

\section{MATERIAIS E MÉTODOS}

Para realização do trabalho, foram separadas duas amostras de um tubo de aço API X52. As duas amostras foram cortadas ao meio no sentido longitudinal em máquina de corte. Após o corte as peças foram preparadas para o processo de soldagem, foram biseladas em um ângulo de $30^{\circ}$ e polidas para descartar qualquer impureza existente em sua superfície. Um par de amostras foi submetida à soldagem pelo processo GTAW (tungstênio inerte gás) e o outro pelo processo SMAW (shielded metal arc welding). Ambas as partes unidas receberam um passe de raiz, dois passes de enchimento e três passem de acabamento.

Ao final da soldagem as duas amostras foram cortadas ao meio para obtenção de um perfil retilínio da face da solda. Com a face exposta e plana as amostras soldadas pelos diferentes processos, GTAW e SMAW passaram por politriz de bancada (AROTEC, modelo Aropol VV) com uma sequência de lixas d'água com diferentes granulometrias (100, 200, 400, 600, 800, 1000, 1500 e 2000). Posteriormente foram polidas com pano de polimento e pasta de diamante, lavadas em água e desengorduradas com álcool. Com as peças lixadas e polidas, seguiu-se então o ataque químico das amostras com uma solução de nital 5\% (álcool+ácido nítrico). $O$ ataque foi realizado por imersão das amostras em solução, durante um período de 50 segundos.

$\mathrm{O}$ ataque citado foi utilizado para a obtenção das macro e micrografias. As macrografias foram obtidas com auxílio de uma câmara digital e por meio de observação visual. Para obtenção das micrografias, foi utilizado um microscópio 
ótico (OLYMPUS, modelo BX51M). Todas as micrografias foram obtidas utilizando o modo campo claro, em diferentes aumentos.

\section{RESULTADOS E DISCUSSÃO}

A fim de realizar o procedimento de soldagem das amostras metálicas, pelos processos SMAW e GTAW, foi realizado uma análise química do aço API X52 e a partir dos resultados obtidos neste ensaio foram escolhidos os consumíveis de soldagem com percentuais de elementos de liga que mais se aproximavam com a composição química do API utilizado. A tabela 1 indica a composição química do aço API X52 e dos consumíveis se soldagem utilizados para o processo SMAW (E 7018-1) e GTAW (ER 70S3) respectivamente.

Tabela 1. Análise química metal base e consumíveis

\begin{tabular}{lcccccccccc}
\hline $\begin{array}{l}\text { Metal } \\
\text { base/consumível }\end{array}$ & $\mathbf{C}$ & Si & $\mathbf{P}$ & Mn & $\mathbf{S}$ & Mo & $\mathbf{C r}$ & $\mathbf{N i}$ & $\mathbf{A l}$ & $\mathbf{F e}$ \\
\hline Aço API X52 & 0,19 & 0,23 & 0,02 & 0,94 & $\ldots$ & 0,01 & 0,04 & 0,017 & 0,02 & Balanço \\
\hline E 7018-1 & 0,12 & 0,8 & 0,03 & 0,9 & 0,03 & 0,04 & $\ldots$ & $\ldots$ & $\ldots$ & Balanço \\
\hline ER 70S3 & 0,15 & 0,75 & 0,025 & 0,9 & 0,035 & 0,015 & 0,015 & 0,015 & $\ldots$ & Balanço \\
\hline
\end{tabular}

A figuras 1 e 2 apresenta a análise macroscópica obtida para a amostras soldadas pelos processos SMAW e GTAW respectivamente. É possível observar, que $O$ ataque utilizado revelou claramente três diferentes zonas em ambas as juntas soldadas: metal de base, ZTA (zona termicamente afetada), e a zona de fusão (a raiz, os passes de preenchimento e acabamento). Não foram observados defeitos visuais ao longo de toda seção da solda.

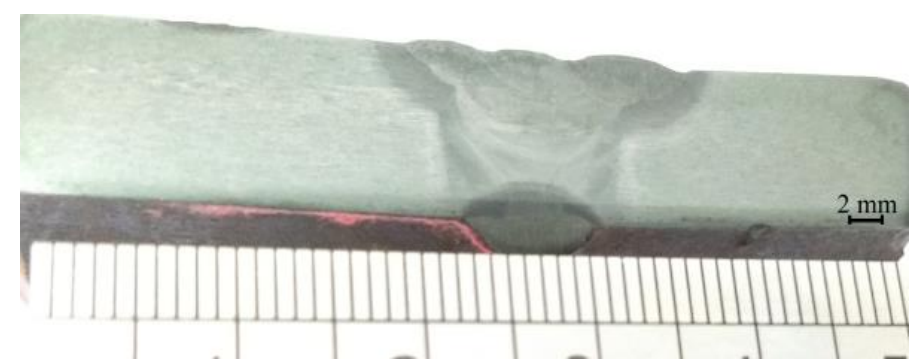

Figura 1. Macrografia da junta soldada do aço API X52 pelo processo SMAW.

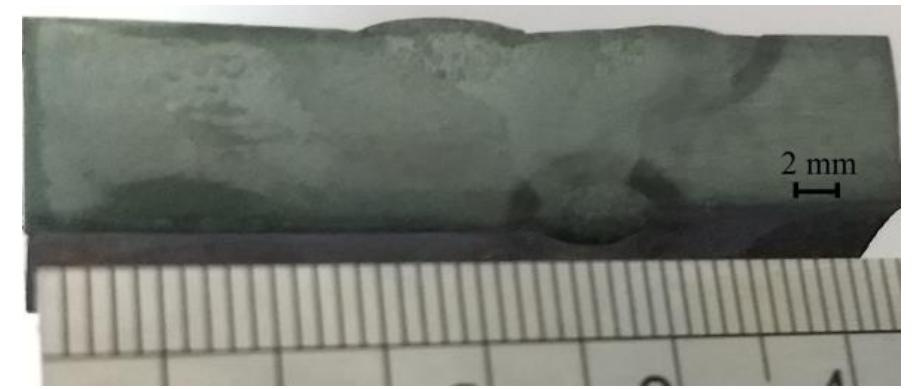

Figura 2. Macrografia da junta soldada do aço API X52 pelo processo GTAW. 
A figura 3 apresenta a micrografia obtida para o metal de base, observa-se claramente a presença de duas fases distintas, perlita (fase escura) e ferrita (fase clara). Verifica-se que ambas as fases se encontram distribuídas em forma de lamelas, na direção do processamento.

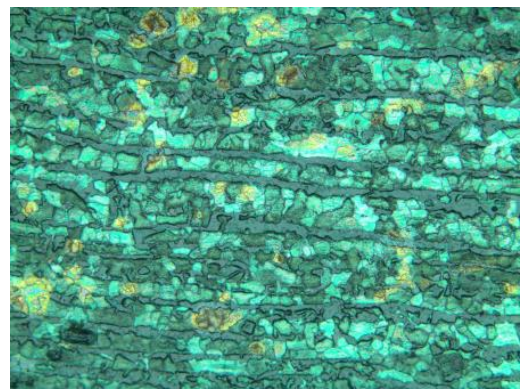

Figura 3. Micrografia do metal de base (MB), ataque Nital $5 \%$.

As figuras 4 e 5 mostram, as micrografias obtidas para a região da zona termicamente afetada (ZTA) e a zona de fusão (preenchimento da solda) para as amostras soldadas pelos processos SMAW e GTAW, respectivamente. É possível verificar que a zona termicamente afetada (ZTA) é ligeiramente maior para a amostra soldada pelo processo SMAW. Observa-se a presença de grãos mais grosseiros na ZTA, para a solda realizada com processo SMAW.
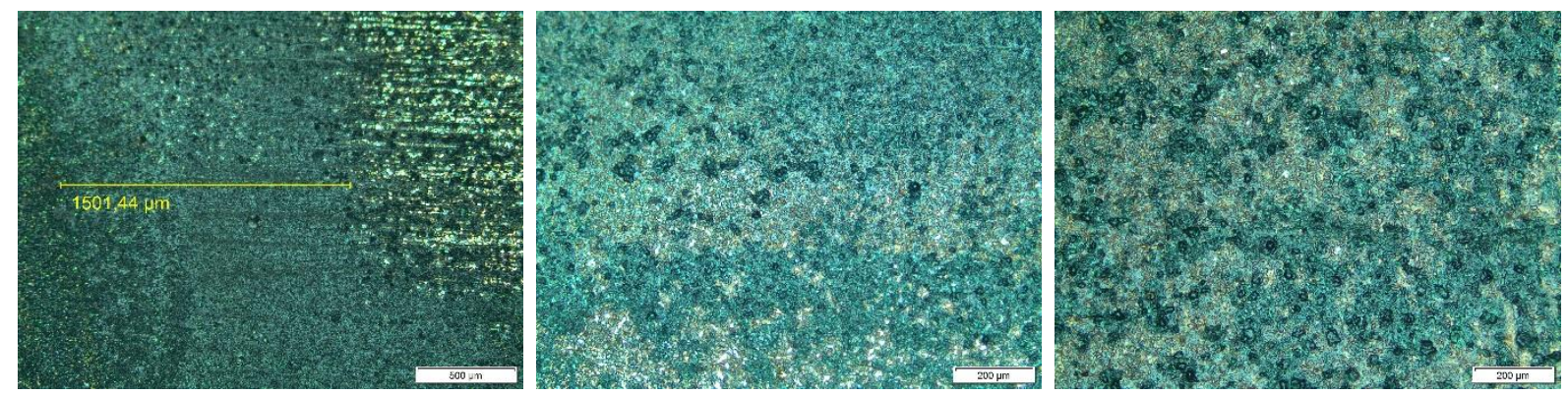

Figura 4. Micrografia da zona termicamente afetada (ZTA) e da zona de fusão (raiz e topo da solda), processo SMAW, ataque Nital $5 \%$.
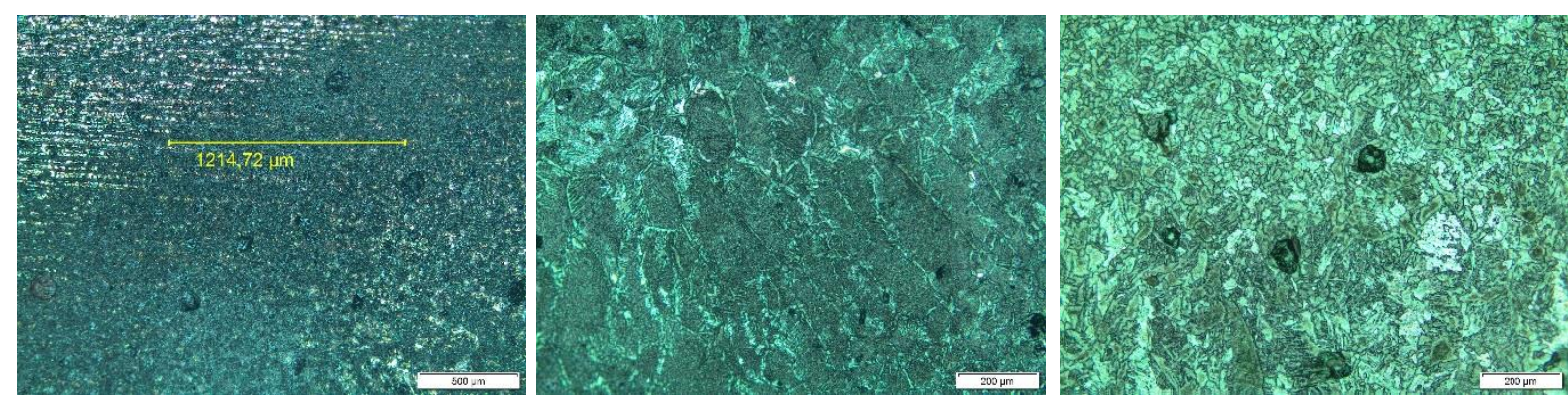

Figura 5. Micrografia da zona termicamente afetada (ZTA) e da zona de fusão (raiz e topo da solda), processo GTAW, ataque Nital $5 \%$.

No entanto, ao observar as regiões adjacentes à raiz e ao topo da solda, é possível verificar uma significativa diferença entre as microestruturas geradas pelos processos SMAW e GTAW. Observa-se sobretudo a presença de grãos de ferrita poligonal para a microestrutura observada no processo SMAW. Por sua vez, é possível observar a presença de diferentes microconstituintes tais como a ferrita primária e ripas de ferrita secundária, na microestrutura gerada pelo processo 
GTAW. As diferenças na microestrutura estão provavelmente associadas às diferenças no aporte de calor e nas taxas de resfriamento entre os dois diferentes processos de soldagem, bem como na diferença de composição química entre os eletrodos empregados.

\section{CONCLUSÃO}

Considerando os resultados observados, é possível concluir que os processos de soldagem utilizados interferem diretamente na microestrutura dos aços. Verificou-se mediante observação da macroestrutura que ambos os processos SMAW e GTAW resultaram em juntas soldadas livre de defeitos. Foi possível observar claramente a presença de três zonas distintas ao longo da junta. A observação microestrutural mostrou que a principal diferença entre os processos ocorreu na região da zona de fusão, bem como nas regiões adjacentes à raiz e ao topo da solda. Observou-se claramente que o processo GTAW, nas condições experimentais avaliadas, gerou uma microestrutura com maior quantidade de microconstituintes em comparação ao processo SMAW. A diferença na microestrutura está provavelmente relacionada com as diferenças de aporte térmico e as diferentes composições químicas dos eletrodos empregados nos respectivos processos de soldagem.

\section{Agradecimentos}

Agradecemos à FAPERJ pelos auxílios concedidos.

\section{REFERÊNCIAS}

1 Soeiro Junior JC, Rocha $D B$, Brandi SD. Uma Breve Revisão Histórica do Desenvolvimento da Soldagem dos Aços API para Tubulações, Soldagem e Inspeção. 2013; 18 (2): 176 - 195.

2 Vargas-Arista $B$, Hallen JM, Albiter $A$. Effect of artificial aging on the microstructure of weldment on API $5 \mathrm{~L}$ X-52 steel pipe, Materials Characterization. 2007; 58: 721-729.

3 Alizadeh $\mathrm{M}$, Bordbar $\mathrm{S}$. The influence of microstructure on the protective properties of the corrosion product layer generated on the welded API X70 steel in chloride solution. Corrosion Science. 2013; 70: 170 - 179.

$4 \mathrm{Yu} \mathrm{H}$. Influences of microstructure and texture on crack propagation path of X70 acicular ferrite pipeline steel. Journal of University of Science and Technology Beijing. 2008; 15 (6): $683-687$.

5 Albuquerque SF, Maciel TM, Santos MA, Bracarense AQ. Avaliação da Microestrutura e Propriedades Mecânicas de Metais de Solda Obtidos por Processos de Soldagem Manual e Automatizado utilizado na Soldagem de Aço API 5L X80. Soldagem e Inspeção. 2011; 16 (4): 322 - 332. 